\title{
An Oxygen Ion Source for the Secondary Ion Mass Spectrometer
}

\author{
HIROSHI NISHIMURA* AND JUN OKANO*
}

(Received 7 March 1975)

\begin{abstract}
An ion source to get an ion beam of oxygen was constructed. A stable ion beam of oxygen was obtained. The current and the diameter of the beam were $1.2 \times 10^{-7} \mathrm{~A}$ and $100 \mu \mathrm{m}$, respectively. The ion source was attached to a secondary ion mass spectrometer as the primary ion source. The preliminary measurements of the isotopic ratios of chromium, iron, and nickel were performed for the sample of stainless steel. The relative sensitivities of $\mathrm{Ti}, \mathrm{V}, \mathrm{Cr}, \mathrm{Mn}$, $\mathrm{Co}$, and $\mathrm{Ni}$ to $\mathrm{Fe}$ were obtained by the use of the standard sample of low alloy steel (NBS, No. 466). The results were compared with those obtained by the primary ions of argon. It was found that the differences of the relative sensitivities among these elements were small for oxygen primaries compared with that for argon primaries.
\end{abstract}

\section{Introduction}

An ion source for secondary ion mass spectrometry is desired to have following characteristics. Those are: high intensity, high stability, excellent focusing property, long life and capability for producing many kinds of ionic species.

For the ppb trace analysis, the high intensity is the most important, and for the point-to -point analysis, the excellent focusing property takes the precedence of the others. It is generally difficult to get the ion source with a long life for active elements. However, in many cases, it is necessary to use the ions of active elements as primaries.

Andersen et $^{{ }^{1}{ }^{1.2)}}$ reported that the secondary ion intensity increased when oxygen ions were used as primaries instead of argon ions. Konishi et al. . $^{3)}$ reported that the increase of the secondary ion yield was observed by introducing oxygen gas into the target chamber up to the pressure of $3 \times 10^{-5}$ Torr.

In order to increase the secondary ion yield and to carry out the isotopic measurement of a trace element in a solid meterial, an ion source for producing oxygen ions has been constructed. The characteristics of the ion source were studied and some preliminary experiments were carried out using the ion source as the primary ion gun of the secondary ion mass spectrometer."

\section{Experimental}

\subsection{Apparatus}

The ion source consists of an ion gun for producing oxygen ions, a drawing out electrode, focusing and deflecting electrodes. The schematic diagram of the ion source is illustrated in Fig. 1. A secondary ion extraction system is also shown.

The ion gun consists of a cylindrical cathode, an anode, and an exit electrode. The cathode was made of tantalum, and the diameter of the cylinder is $6 \mathrm{~mm}$. It was mounted on a cathode holder of stainless steel. The anode and the exit electrode were both made of magnetic stainless steel. A permanent magnet of ferrite was put between these two electrodes, and the magnetic flux was concentrated at the exit aperture, whose diameter is

* Institute of Geological Sciences, College of General Education, Osaka University, Toyonaka, Osaka 560 


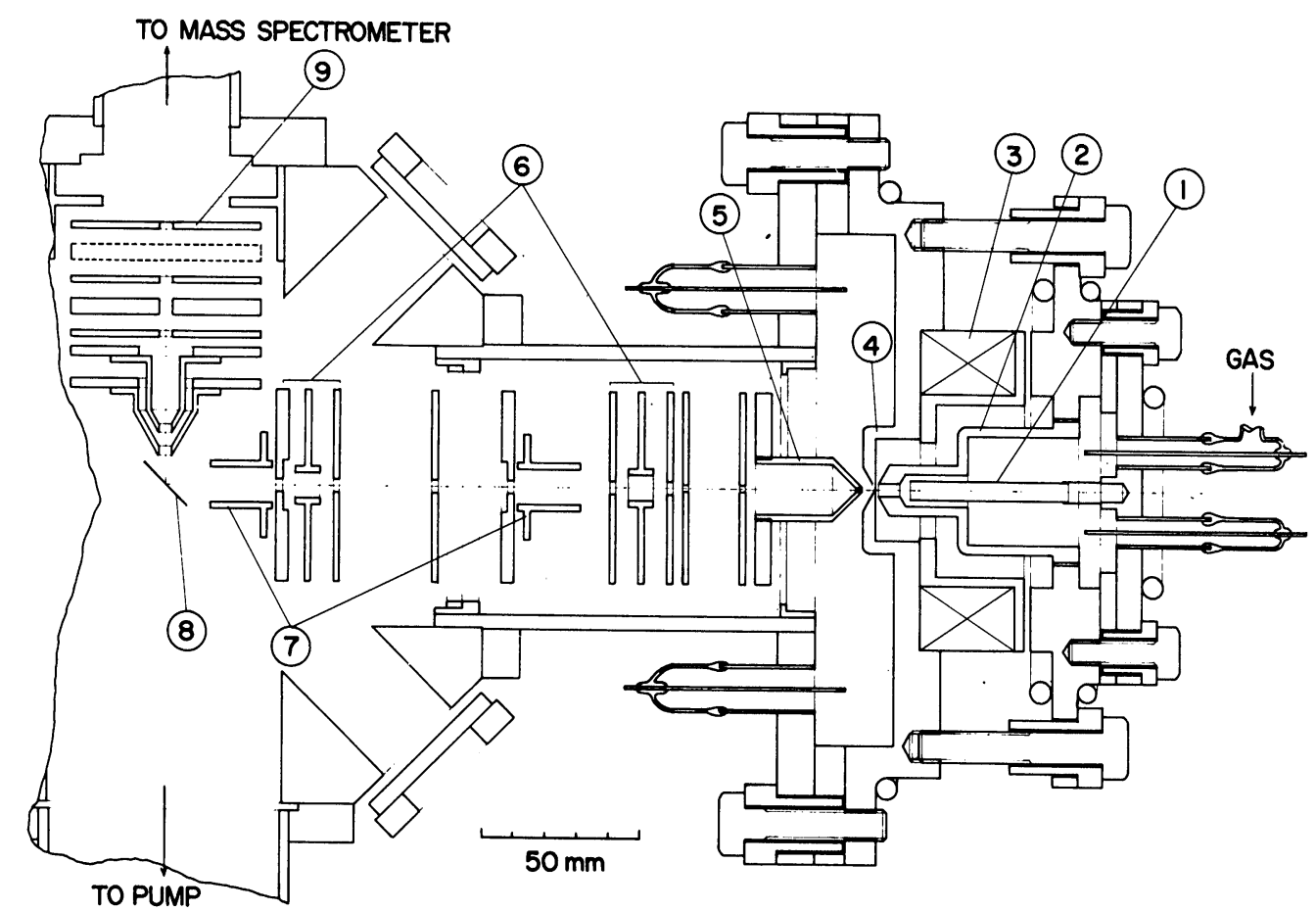

Fig. 1. Schematic diagram of the ion source for producing a primary ion beam of oxygen. The secondary ion extraction system is also shown.

(1) cylindrical cathode, (2) anode, (3) permanent magnet of ferrite, (4) exit electrode, (5) accelerating electrode,

(6) Einzel lenses, (7) deflecting electrodes, (8) target holder, (9) main slit for the following mass spectrometer.

$0.4 \mathrm{~mm}$. The strength of the magnetic field is about 700 gauss at the aperture. These electrodes were cooled by oil. The O-rings of Viton were used for the vacuum seal. The insulation among the electrodes was performed by spacers which were made of alumina.

The drawing out electrode, Einzel lenses, and deflecting electrodes were made of stainless steel. They were set after being etched electrolytically and were insulated each other by spacers of steatite. The system can be slided in the direction of the axis of the primary ion beam, and the distance from the target to the lens can be adjusted. The set of the second Einzel lens and deflecting electrodes can be removed from other electrodes, if necessary. In order to minimize the effect of residual gas molecules, the trap of liquid nitrogen was attached behind the target holder.
The secondary ion extraction system consists of an exit electrode, an accelerating electrode, two sets of half plates for focusing and deflecting the secondary ions, and an electrode for the entrance slit of the following double focusing mass spectrometer. This system can also be slided in the direction of the axis of the secondary ion trajectories, so that the distance between the target and the exit electrode can be adjusted.

\subsection{Characteristics}

The stability and intensity of the primary ion beam of oxygen was studied. A typical working condition is listed in Table 1. The accelerating voltage for the primary ions can be supplied up to $15 \mathrm{kV}$, and that for the secondary ions, up to $3 \mathrm{kV}$.

A stable ion beam of oxygen was obtained a few minutes after starting the discharge. A 
An Oxygen Ion Source for the Secondary Ion Mass Spectrometer

Table 1. The typical working condition of the ion source for oxygen primary ions.

\begin{tabular}{l|l}
\hline Ionic species & oxygen $\left(\mathrm{O}_{2}^{+}, \mathrm{O}^{+}\right)$ \\
Accelerating voltage of primary ion & $9 \mathrm{kV}$ \\
Discharge voltage & 500 to $700 \mathrm{~V}$ \\
50 to $80 \mathrm{~mA}$ & about $4 \mathrm{kV}$ \\
Discharge current & about $5.5 \mathrm{kV}$ \\
& $1 \mathrm{kV}$ \\
Potential for Ein el lens $\left\{\begin{array}{l}\text { first } \\
\text { second }\end{array}\right.$ & about $5 \times 10^{-7}$ Torr \\
Pressure $\left\{_{\text {with oxygen gas }\left\{\begin{array}{l}\text { target chamber } \\
\text { at the cathode }\end{array}\right.}^{\text {about } 3 \times 10^{-5} \text { Torr }}\right.$ \\
\hline
\end{tabular}

chart indicating the stability of the primary ion current is shown in Fig. 2. The current and diameter of the beam were about $1.2 \times 10^{-7} \mathrm{~A}$ and $100 \mu \mathrm{m}$ respectively in this case. The diameter was estimated by measuring the ion current passing through the movable slit.

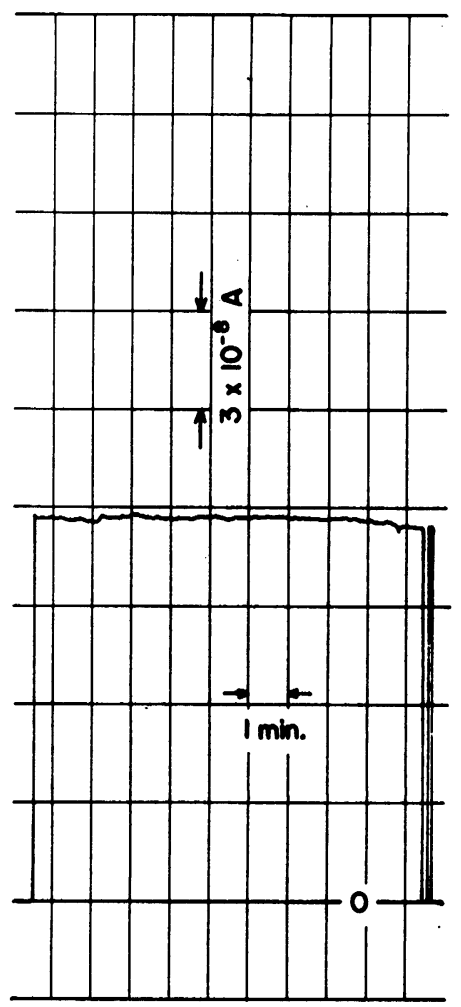

Fig. 2. Stability measurement of the primary ion current of oxygen.

\section{Applications and Discussion}

\subsection{Isotopic Ratios}

Preliminary measurements of the isotopic ratios were.carried out for the sample of stainless steel. A mass spectrum obtained is shown in Fig. 3. The isotopic ratios of ${ }^{52} \mathrm{Cr} /{ }^{50} \mathrm{Cr}$, ${ }^{52} \mathrm{Cr} /{ }^{53} \mathrm{Cr},{ }^{56} \mathrm{Fe} /{ }^{54} \mathrm{Fe}$, and ${ }^{58} \mathrm{Ni} /{ }^{60} \mathrm{Ni}$ were measured. The results are illustrated in Fig. 4. The ratio of ${ }^{56} \mathrm{Fe} /\left({ }^{57} \mathrm{Fe}+{ }^{56} \mathrm{FeH}\right)$ is also shown in the figure. The holizontal line corresponding to each isotopic ratio indicates the natural abundance ratio obtained from the literature. The correction for metal hydride was not done.

The production rate of iron hydride was calculated to be about 2 percent from the peak height ratio. It was 5 to 7 percent in the earlier experiment where the primary ions of argon were used. Thus the effect of metal hydride could be decreased by using the oxygen ions as primaries.

\subsection{Relative Sensitivities}

A standard sample of low alloy steel from NBS (No. 466) was analyzed, in order to get the relative sensitivities of elements. They were compared with those obtained by the argon primary ions. The relative sensitivities of $\mathrm{Ti}, \mathrm{V}, \mathrm{Cr}, \mathrm{Mn}, \mathrm{Co}$, and $\mathrm{Ni}$ to $\mathrm{Fe}$ were obtained. The contents of the elements in the standard sample, which were analyzed chemically by National Bureau of Standards are 
H. Nishimura and J. Okano

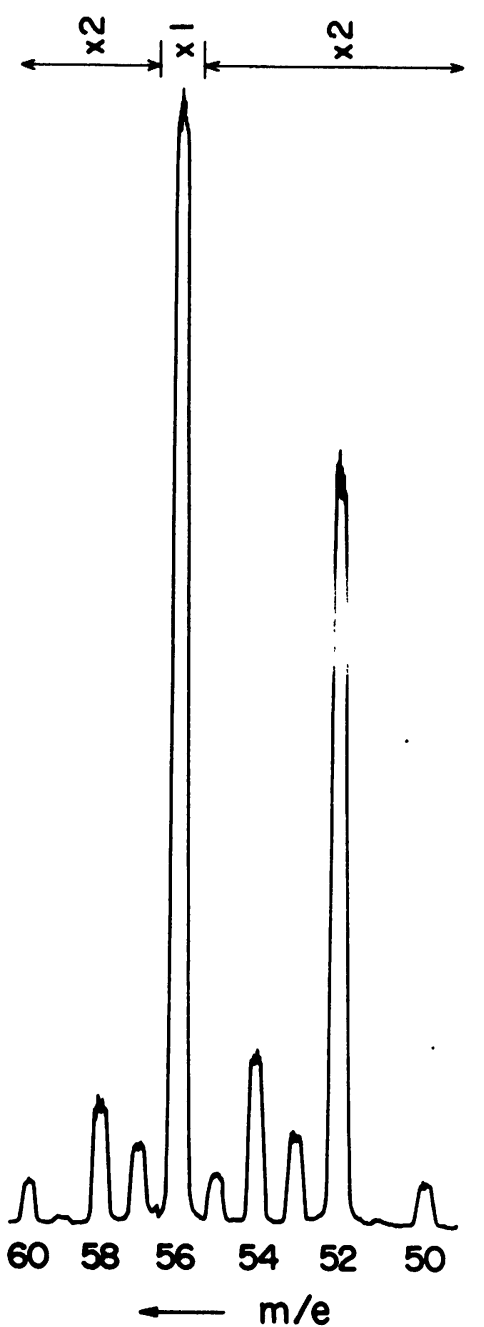

Fig. 3. Mass spectrum obtained for the sample of stainless steel.

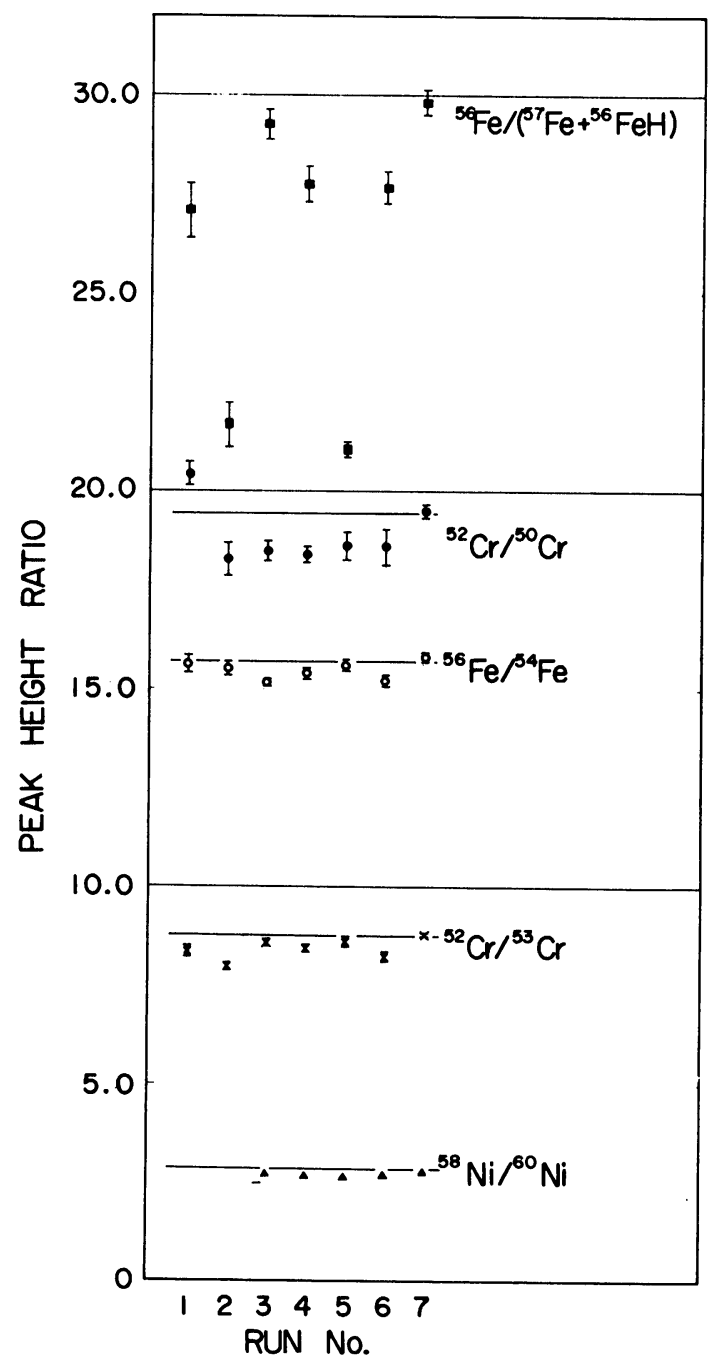

Fig. 4. Peak height ratios of $\mathrm{Cr}, \mathrm{Fe}$, and $\mathrm{Ni}$ in the sample of stainless steel. Each run corresponds to the different experimental date. The correction for metal hydride was not done.

Table 2. The content of each element in the standard sample of NBS (No. 466).

\begin{tabular}{l|cccccc}
\hline & $\mathrm{Ti}$ & $\mathrm{V}$ & $\mathrm{Cr}$ & $\mathrm{Mn}$ & $\mathrm{Co}$ & $\mathrm{Ni}$ \\
\hline Content (wt. \%) & .075 & .007 & .011 & .113 & .046 & .033 \\
\hline
\end{tabular}

listed in Table 2.

The diagrams of the relative sensitivities of the elements as a function of atomic number were illustrated in Figs. 5 and 6. Figure 5 corresponds to the case of bomberd- ment by oxygen primary ions, and Fig. 6, argon primary ions. In both diagrams, each point fits in a straight line on the whole. The gradient of the line was smaller in the case of the oxygen primary ions than the case of the argon primary 
An Oxygen Ion Source for the Secondary Ion Mass Spectrometer



Fig. 5. Relative sensitivity as a function of atomic number. The primary ions were oxygen ions. The standard sample of NBS (No. 466) was used.

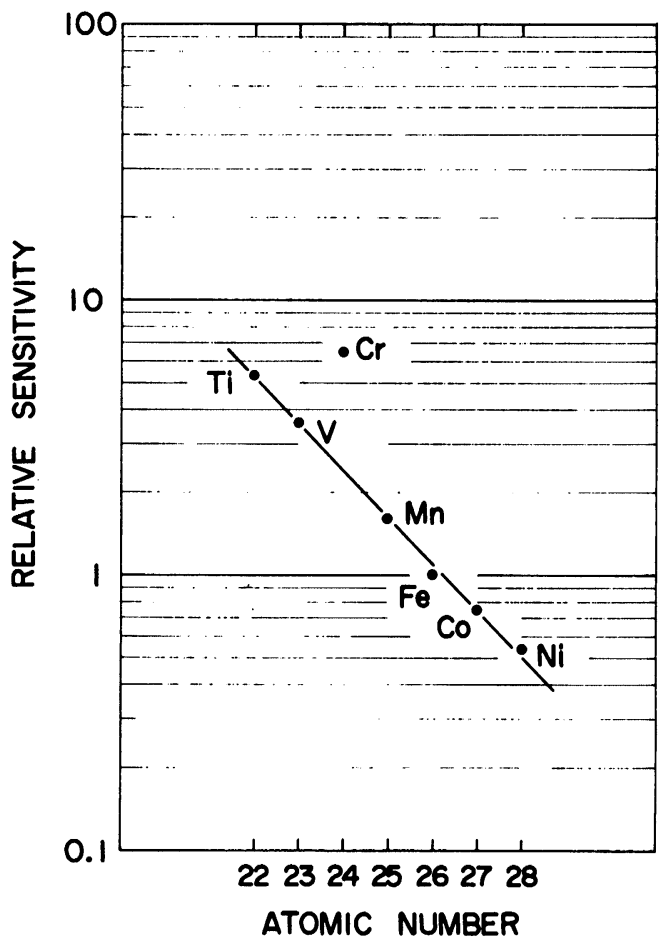

Fig. 6. Relative sensitivity as a function of atomic number. The primary ions were argon ions. The standard sample of NBS (No. 466) was used.

$$
-13-
$$




\section{H. Nishimura and J. Okano}

ions.

The anomaly of the relative sensitivity of chromium is seen in Fig. 5. This anomaly is not observed in the case of argon primary ions. The similar result was reported by Andersen et al."

The life of the ion source was about 50 hours. The chathode is heated and oxydized under the discharge in the atmosphere of oxygen gas, and the erosion proceeds during the operation of the ion source. This is the limiting factor of the life.

The beam current increases with the increase of the discharge current. A higher beam current than that given in this paper can be obtained with the higher discharge current, but the cooling plobrem becomes serious in this case. By the improvement of the cooling power, the increase of the beam current may be achieved.
In order to keep the pressure in the analyzer chamber as low as possible, an improvement of the pumping system is now planning. This is. especially necessary for the measurements of trace elements, because the high $\mathrm{S} / \mathrm{N}$ ratio is essentially important in this case.

By the improvements mentioned above, the analysis of trace elements in the solid sample may be performed with a high sensitivity using the oxygen ion source.

\section{References}

1) C. A. Andersen, Intern. J. Mass Spectrom. Ion Phys., 2, 61 (1969).

2) C. A. Andersen and J. R. Hinthorne, Science, 175, 853 (1972).

3) K. Kusao, N. Nakamura and F. Konishi, Mass Spectroscopy, Japan, 21, 53 (1973).

4) H. Nishimura and J. Okano, Japan. J. Appl. Phys., 8, 1353 (1969).

5) C. M. Lederer, J. M. Hollander and I. Perlman, "Table of Isotopes”, John Wiley, New York (1967), 6th ed., p. 18. 